\title{
Percepções do Turismo em Atrativos da APA Caverna do Maroaga, Presidente Figueiredo/AM
}

\section{Perceptions of Tourism in Maroaga Cave APA and Presidente Figueiredo Attractions in Amazonas}

\section{Percepciones del Turismo en Atractivos Naturales de la APA Caverna del Maroaga, Presidente Figueiredo/AM}

\author{
João Rodrigo Leitão dos Reis ${ }^{1}$ \\ Julio César Rodríguez Tello ${ }^{2}$ \\ Christina Fischer ${ }^{3}$
}

\begin{abstract}
Resumo
O turismo desenvolvido nos atrativos naturais de forma inadequada é a principal fonte de pressão e degradação desses locais, sendo necessário obter informações sobre o processo de visitação. Com esse intuito, foi analisada a percepção e preferências dos visitantes dois atrativos turísticos naturais da Área de Proteção Ambiental (APA) Caverna do Maroaga, Presidente Figueiredo/AM, quanto ao gerenciamento e conservação dos locais. Utilizou-se o método da pesquisa exploratória a partir de um estudo de Caso, sendo realizadas 30 entrevistas. Detectou-se que os visitantes tem maior interesse em visitar cachoeiras, e que há ausência de segurança, vigilância e de infraestrutura adequadas para permanência, estadia e alimentação nos locais, além da presença de impactos ambientais. Cabendo aos proprietários proporcionar melhorias com a aplicação de medidas de gestão conforme as condições biofísicas dos locais, e ao Poder Público ordenar o turismo na APA, assegurando a proteção efetiva dos seus atrativos.
\end{abstract}

Palavras-chave: visitação; atrativos naturais; unidade de conservação.

\footnotetext{
${ }^{1}$ Geógrafo, UFAM. Mestre em Ciências Florestais e Ambientais, UFAM. Discente de Mestrado do Programa de Pós-Graduação em Ciências Florestais e Ambientais da Universidade Federal do Amazonas. Chefe de Departamento da Secretaria Executiva Adjunta de Compensações e Serviços Ambientais da Secretaria de Estado do Meio Ambiente e Desenvolvimento Sustentável do Amazonas - SEACA/SDS. Brasil. E-mail: jrlreis@gmail.com.

${ }^{2}$ Engenheiro Florestal pela Universidad Nacional de La Amazonía Peruana - UNAP. Mestre Stricto Sensu em Engenharia Florestal pela Universidade Federal do Paraná - UFPR. Doutor em Ciências Biológicas e Recursos Naturais pelo Convênio Instituto Nacional de Pesquisas da Amazônia/Universidade Federal do Amazonas. Professor Titular da Universidade Federal do Amazonas - UFAM. Coordenador, docente e pesquisador do Programa de Pós-Graduação Stricto Sensu em Ciências Florestais e Ambientais do Curso de Especialização Lato Sensu em Gestão Ambiental Empresarial. Coordenador do Grupo de Pesquisa Ecologia, Gestão Ambiental e Áreas Protegidas - ECOGAP. Brasil. E-mail: jucerote@ hotmail.com.

${ }^{3}$ Engenheira de Pesca pela Universidade Federal do Amazonas. Mestrado em Biologia de Água Doce e Pesca Interior pelo Instituto Nacional de Pesquisas da Amazônia. Analista Ambiental do Instituto de Proteção Ambiental do Amazonas, cedida à Secretaria de Estado do Meio Ambiente e Desenvolvimento Sustentável-SDS, atuando no Centro Estadual de Unidades de Conservação - CEUC. Brasil. E-mail: chrisfischerpeixes@gmail.com.
} 


\begin{abstract}
The tourism developed on the natural attractions inappropriately is the main source of pressure and degradation of these places, finding it necessary to obtain information on the visitation process. Having this intuition, the perception and preferences were analyzed in the two natural tourist attraction of the Maroaga Cave Environmental Protection Area (APA) and Presidente Figueiredo/AM, regarding the management and conservation of the areas. Exploratory research was used from a Case Study, having done 30 interviews. It was detected that the visitors were more interested in visiting waterfalls, and that there is a lack of security, watchfulness, and adequate infrastructure for stays and having meals in these places, along with the presence of environmental impacts. It is up to the owners to make improvements by applying measures of administration according to the biophysical conditions of these places, and it is up to the Public Service to maintain order within the APA tourism, ensuring the effective security of the attractions.
\end{abstract}

Keywords: visitation; natural attractions; conservation unit.

\title{
Resumen
}

El turismo desarrollado inadecuadamente en los atractivos naturales es la principal fuente de presión y degradación de esos locales. Así es necesario obtener informaciones y investigar el proceso de visitación. En este trabajo fue investigada la percepción y preferencias de los visitantes de dos atractivos turísticos naturales de la Área de Protección Ambiental (APA) Caverna del Maroaga, Presidente Figueiredo/AM, en relación al gerenciamento y al estado de conservación de cada sitio. El método de investigación exploratória fue utilizada a través de estudios de caso. Fueron realizadas 30 entrevistas con los visitantes. Los resultados obtenidos detectaron que los visitantes tienen mayor interés en visitar cascadas, y que hay ausencia de seguridad, vigilancia y de infraestrutura adecuadas para la permanencia, estancia y alimentación en los sitios estudiados. Además, hay presencia de impactos ambientales en los atractivos naturales. Los propietarios deben proporcionar mejores condiciones a sus visitantes a través de la aplicación de las medidas de gestión ambiental según las condiciones biofísicas de los sitios; y al Poder Público, ordenar el turismo en la APA y asegurar a los atractivos su protección efectiva.

Palabras clave: visitación; atractivos naturales; áreas protegidas.

\section{Introdução}

O turismo desenvolvido nos atrativos naturais de forma inadequada para atendimento aos segmentos do mercado é a principal fonte de pressão e eventual ameaça de degradação nesses locais, mesmo quando enquadrados sob alguma tipologia de áreas legalmente protegidas. Esse 
aspecto influencia na durabilidade de uso desses locais, comprometendo a integridade ambiental de seus atributos, frente à ausência de administração e monitoramento da visitação, adicionado à inexistência de instrumentos normativos e medidas de gestão que assegurem sua proteção efetiva.

Soma-se a isso, a inexistência de instrumentos normativos e medidas de gestão (Takahashi, 2004; Coriolano, 2006; Queiroz, 2006) que assegurem a proteção efetiva dessas áreas. Uma vez que, o processo de mudança de um lugar para adequá-la a função turística, na maioria das vezes, não consegue sincronizar o ritmo e o volume da exploração dos recursos com a capacidade que o meio ambiente oferece (Salva, 1996 citado por Coriolano, 2006). Assim o crescimento sem planejamento, a descaracterização ambiental e a perda da originalidade das destinações turísticas podem ser apontadas para ilustrar as conseqüências da ausência de planejamento das atividades turísticas em núcleos receptores (Queiroz, 2006).

Devido ao leque com opções de valor e uso, o turismo desenvolvido em áreas naturais está muito segmentado. As modalidades que podem ser desenvolvidas são numerosas, implicando em formas diferentes de contato com a natureza, com uma grande diversidade de atividades praticadas por usuários de diferentes perfis (Roncero-Siles, 2003).

Segundo Ribeiro (2002) o ecoturismo é um segmento da atividade turística que utiliza, de forma sustentável, o patrimônio natural e cultural, incentiva sua conservação e busca a formação de consciência ambientalista através da interpretação do ambiente, promovendo o bem-estar das populações envolvidas. Desta forma, a relação unidade de conservação/visitante é uma relação de troca mútua de experiências; o administrador da unidade de conservação precisa do visitante para ajudar a justificar a maneira pela qual as unidades de conservação estão sendo gerenciadas, e o visitante necessita do administrador da unidade de conservação para lhe ajudar e proporcionar uma experiência de alta qualidade (Grahn, 2004).

O desenvolvimento sustentável em relação ao ecoturismo é difícil de ser alcançado por causa da sua expansão extraordinária e da pressão da demanda pelo acesso às áreas naturais. Neste caso, a questão é como tal demanda deve (e se ela deve) ser controlada (Wearing \& Neil, 2001). Para Kinker (2002), mesmo que não sejam criados centros de visitação bem estruturados, deve-se adotar de imediato, medidas para assegurar que esse crescente número de visitantes para que não cause impacto negativo nos valores da biodiversidade das áreas 
protegidas. Os efeitos negativos do ecoturismo são, em grande parte, decorrentes do fato de a visitação muitas vezes preceder a administração e o planejamento efetivos. Há, portanto, a necessidade de formular e implantar estratégias de planejamento adequadas para assegurar que a expansão futura do ecoturismo aconteça de acordo com os princípios do desenvolvimento sustentável (Wearing \& Neil, 2001).

No Brasil, como boa parte dos atrativos naturais está localizado em Unidades de Conservação, os administradores dessas áreas tem a difícil tarefa de conciliar esse uso com a conservação dos recursos naturais e culturais sem degradar o ambiente (Takahashi, 2004). De acordo com Magro (2009) os termos uso público e recreação quando relacionados às áreas naturais são utilizados para definir o uso e as atividades não administrativas praticadas nestes locais. A recreação consiste em atividades de diversão praticadas durante o tempo livre e é o termo adotado na linguagem técnica internacional pelos especialistas em lazer. O Uso público, termo adotado pelos órgãos oficiais, ligados ao manejo de áreas naturais no Brasil, pode ser definido como o usufruto feito pelo público, quer seja recreacionista, pesquisador ou religioso.

Nesse sentido, o Ministério do Meio Ambiente (MMA) por meio da Portaria $\mathrm{n}^{\circ}$ 120, de 12 de abril de 2006 (MMA, 2006 a), aprovou o documento "Diretrizes para visitação em Unidades de Conservação (UC)", no intuito estabelecer recomendações e orientações aos gestores de UC no processo de realização da atividade. Ainda de acordo com a Lei $\mathrm{n}^{\circ}$ 9.985, de 18 de julho de 2000, que instituiu o Sistema Nacional de Unidades de Conservação da Natureza (SNUC), as UCs podem receber visitação turística, com exceção das categorias Reserva Biológica (REBIO) e Estação Ecológica (ESEC), aonde são permitidas apenas ações de interpretação e educação ambiental. Cabe ressaltar que a categoria “Área de Proteção Ambiental” (APA) é uma das mais flexíveis a ações de restrição ao uso dos recursos naturais (Pádua, 2001).

Para compatibilizar objetivos tão distintos com a conservação da biodiversidade, a recreação e a interpretação da natureza, é essencial pesquisar tanto sobre as características dos visitantes e os tipos de usos praticados, bem como, conhecer as condições ambientais do local. Os dados devem subsidiar as decisões de manejo, assegurando uma elevada qualidade nas oportunidades de recreação (Takahashi, 2004).

Nesse sentido, diversos estudos foram realizados sobre visitação em áreas naturais, porém grande parte focalizada na detecção de impactos ambientais em decorrência do turismo e 
sobre a capacidade de carga ou suporte das áreas para atendimento a demanda turística, podese citar como exemplo o estudo desenvolvido por Roncero-Siles (2003) no qual discute a Modelagem espacial para atividades de visitação pública em áreas naturais; a pesquisa realizada por Magro (1999) sobre a detecção dos impactos de uso público em uma trilha do Parque Nacional de Itatiaia; e os estudos sobre a caracterização da visitação, identificação do perfil, percepção e preferências dos visitantes e sobre a detecção dos impactos ocasionados pelo turismo em áreas naturais, cujos trabalhos desenvolvidos por Takahashi (2004) e Takahashi e Milano (2002), foram precursores desses estudos no Brasil.

No Amazonas o Decreto Estadual n ${ }^{\circ}$. 30.873, de 28/12/2010, tem o intuito de estabelecer as diretrizes de uso público para as UC estaduais e orientar a elaboração dos instrumentos de planejamento e gestão para o desenvolvimento de atividades, de acordo com suas categorias de manejo. Neste Decreto em seu art. $2^{\circ}$, o uso público é definido como a visitação com finalidade recreativa, esportiva, turística, histórica-cultural, educacional e de interpretação e conscientização ambiental, que se utiliza dos atrativos das unidades de conservação e da infraestrutura e equipamentos eventualmente disponibilizados para tal. Já o ecoturismo é definido como um segmento da atividade turística que utiliza de forma sustentável, o patrimônio natural e cultural, incentiva a sua conservação e busca a formação de uma consciência ambientalista através da interpretação do ambiente, promovendo o bem estar das populações.

Na região da Área de Proteção Ambiental (APA) Caverna do Maroaga são raros os estudos desenvolvidos junto aos visitantes de áreas naturais com ou sem proteção oficial buscando saber sobre suas preferências e caracterização do estado do uso público desses locais (estado de conservação, impactos ambientais etc.). Além disso, na APA pesquisas voltadas para detecção da capacidade de carga ou de suporte dos locais são praticamente inexistentes. No entanto, quanto ao diagnóstico ambiental das áreas pode-se citar a pesquisa desenvolvida por Gadelha e Alecrim (2006), onde detectaram e analisaram os impactos ambientais em três atrativos naturais (Cachoeira da Porteira, Cachoeira do Santuário e Caverna do Maroaga). Salienta-se ainda, que um dos agravantes sobre os efeitos do turismo na APA é o fato de não possuir plano de manejo e medidas de gestão e regulamento de uso público (capacidade de carga, controle de visitantes, etc.) para as áreas naturais que abrange, podendo ser considerado a principal ameaça a integridade ambiental dos seus atrativos (Sessegolo et. alli, 2004; Reis \& Freitas, 2008). 
Assim frente à carência de estudos na APA foi realizada análise do estado de uso público de dois atrativos naturais e preferências dos visitantes, com base na percepção de seus usuários.

\section{Material e Métodos}

\section{1. Área de estudo}

A APA Caverna do Maroaga possui 374.700 ha, equivalente a 14\% do município de Presidente Figueiredo/AM. Está localizada entre as coordenadas geográficas $01^{\circ} 11^{\prime} 35^{\prime \prime}$ a $02^{\circ} 16^{\prime} 02^{\prime \prime}$ de latitude sul e $59^{\circ} 17^{\prime} 24^{\prime \prime}$ a $60^{\circ} 25^{\prime} 12^{\prime \prime}$ de longitude oeste de Greenwich. Essa APA foi criada com o objetivo de patrimônio espeleológico do município. São encontradas na APA áreas com atrativos naturais com ou sem uso turístico direto (Fig. 1.), das quais destacam-se: a) Cachoeira da Porteira e b) RPPN Cachoeira Santuário.

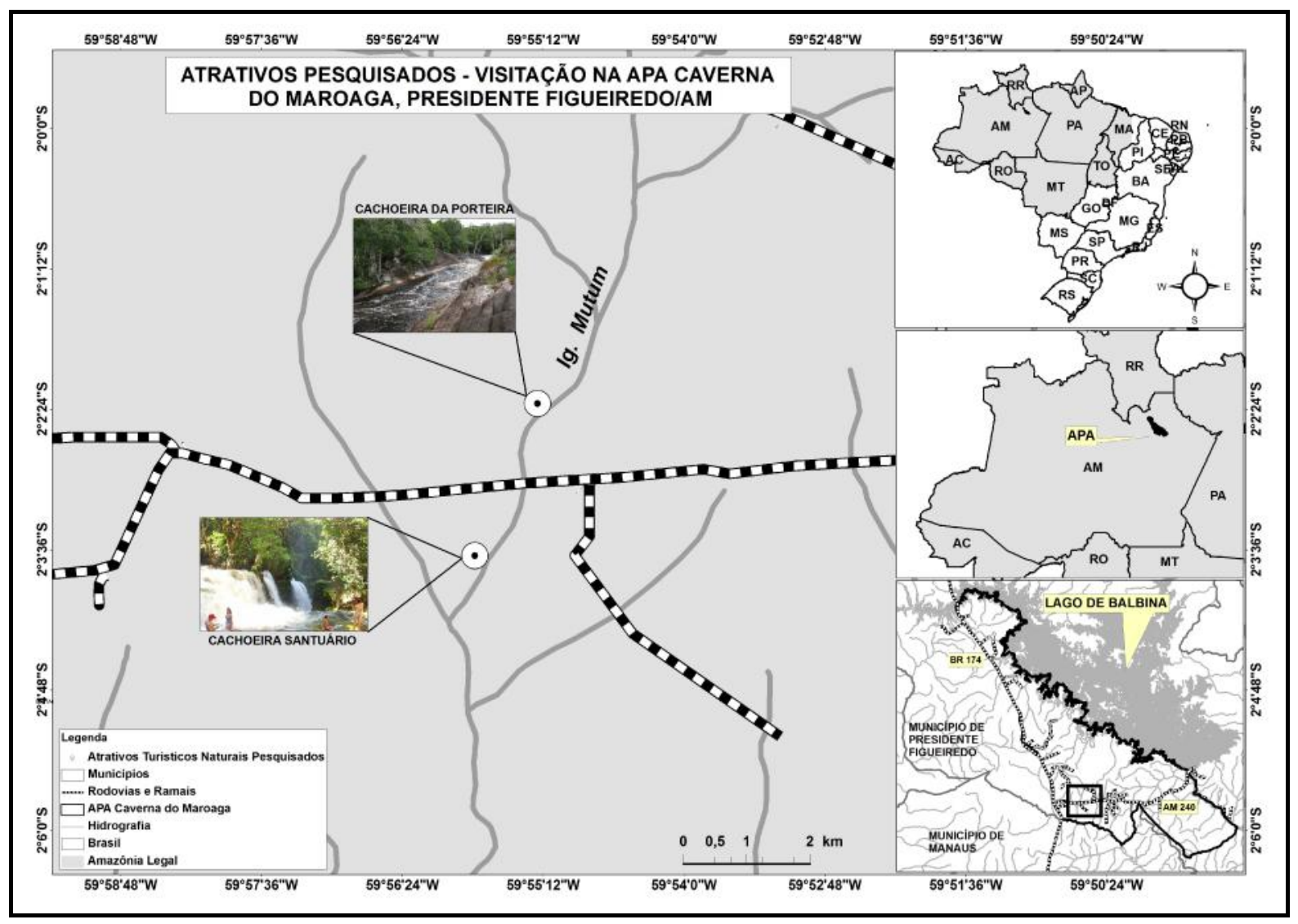

Fig. 1. - Atrativos da APA Caverna do Maroaga. Fonte: Reis, 2010. 
A Cachoeira da Porteira é um atrativo turístico natural localizado na AM-240 km 13 margem esquerda, no ramal da Fazenda Cachoeira da Porteira $\mathrm{Km} \mathrm{1,5.} \mathrm{Localiza-se} \mathrm{entre} \mathrm{as}$ coordenadas geográficas $02^{\circ} 02$ ' $21^{\prime}$ ' latitude sul e $59^{\circ} 55^{\prime} 12^{\prime}$ ' longitude oeste. A Reserva Particular do Patrimônio Natural (RPPN) federal Cachoeira do Santuário localiza-se também na AM-240 km 12 margem direita. $\mathrm{O}$ atrativo localiza-se entre as coordenadas geográficas $02^{\circ}$ 03' 02" latitude sul e 59 $55^{\circ}$ '45' longitude oeste. Esta RPPN foi instituída por meio da Portaria $n^{\circ}$. 139/98-N, de 02 de outubro de 1998. Fora dos domínios da RPPN há na propriedade, infraestrutura anexa à pousada, restaurante e auditório, sendo um empreendimento turístico modelo para a região de Presidente Figueiredo.

\subsection{Métodos e etapas da pesquisa}

Utilizou-se o método da Pesquisa Exploratória desenvolvida a partir de um Estudo de Caso (Yin, 2005), com pesquisa bibliográfica e documental, e investigação de campo, com aplicação de ferramentas de coleta de informações. No âmbito da pesquisa entende-se: a) Visitantes de áreas naturais: são os turistas, pesquisadores e comunitários que visitam a área esporadicamente ou permanentemente, desenvolvendo algum tipo de atividade de recreação e usufruto das mesmas, além de proporcionar algum ganho financeiro aos gestores e comunitários; b) Usuários de áreas naturais: são os proprietários/gestores, visitantes e comunitários. Foram aplicadas 30 entrevistas roteirizadas junto aos visitantes de 02 áreas com atrativos naturais da APA, sendo a Cachoeira do Santuário e a Cachoeira da Porteira.

Em cada atrativo foram aplicados 15 questionários, constituídos por 15 perguntas. A realização das entrevistas teve como parâmetro à importância e representatividade das amostras, sendo escolhidas aleatoriamente entre adultos de todos os gêneros, tendo como único critério o fato dos entrevistados serem visitantes dos locais. Os dois atrativos foram escolhidos para averiguar a percepção do visitante quanto ao uso do local, e compará-los em virtude do primeiro ser uma Reserva Particular do Patrimônio Natural (RPPN) federal sobreposta a APA, e o segundo não possuir proteção oficial, apesar de também estar inserido nos limites da UC em estudo. As respostas de cada pergunta foram agrupadas por aproximação dos termos utilizados, visto que as questões eram abertas, permitindo o tratamento estatístico. 
As entrevistas obedeceram às seguintes etapas: a) Contato institucional junto aos proprietários para acesso aos seus atrativos; e, b) Solicitação de autorização para entrevistar os visitantes das áreas selecionadas. A análise integrada das informações foi realizada por meio de matrizes de interação e listagem de controle.

\section{Resultados e Discussão}

Saber sobre as percepções e preferências dos visitantes é essencial. Para isso é necessário conhecer a origem dos visitantes e seus interesses. Detectou-se que o perfil dos visitantes em ambos os atrativos "Cachoeira da Porteira" e "Cachoeira Santuário", é caracterizado por cerca de $20 \%$ dos entrevistados residentes na área rural e $80 \%$ da área urbana, confirmando a grande participação dos moradores das sedes municipais no uso de áreas naturais.

Descobrir os fatores que proporcionam a visitação turística em uma área natural propicia o surgimento de novos arranjos administrativos e valorização da paisagem. Desta forma, quanto à definição do grau de atratividade dos locais, detectou-se que os visitantes são mais voltados a concepção de interação com o meio natural e a prática de atividades de entretenimento (Fig. 2.).

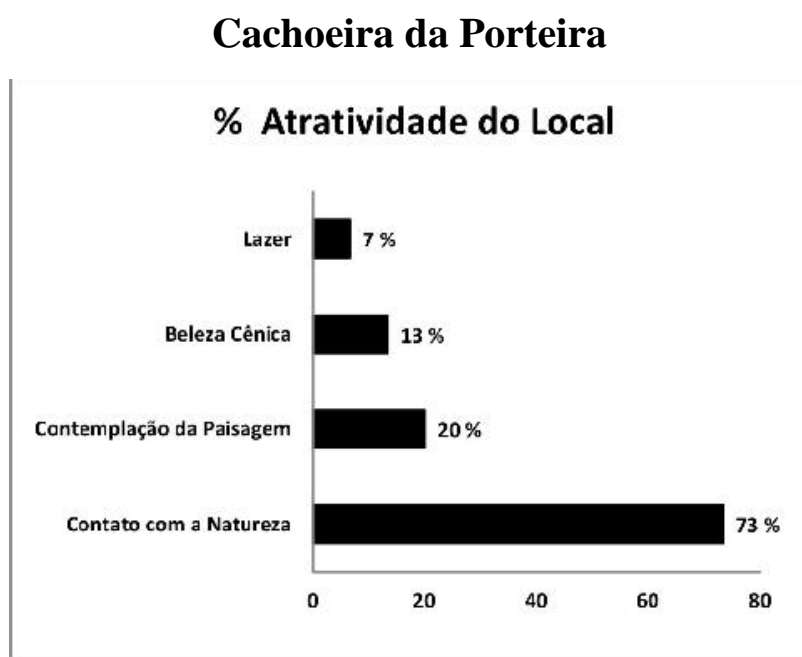

a

\section{Cachoeira Santuário}

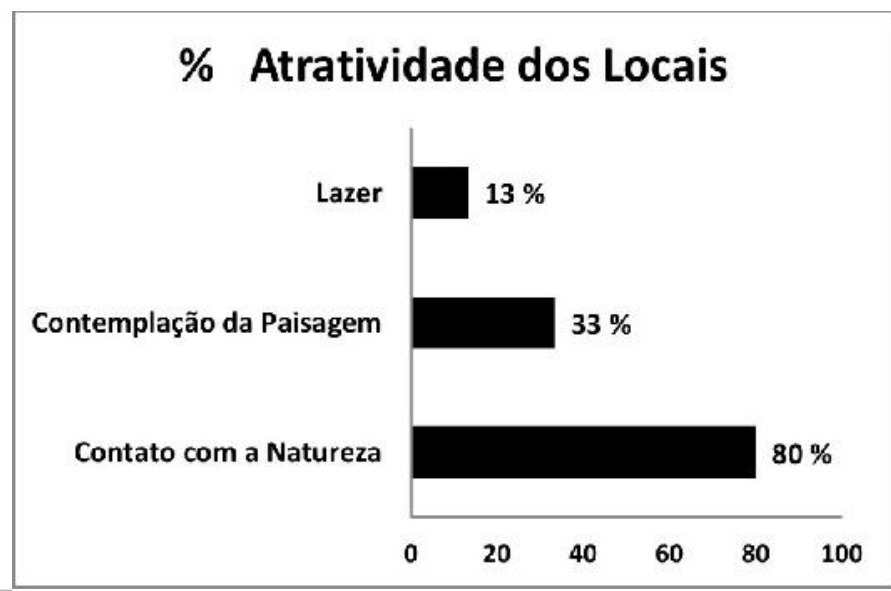

$\mathrm{b}$

Fig. 2. - Atratividade dos Locais: a) Entrevistados da Cachoeira da Porteira; e b) Entrevistados da Cachoeira Santuário. Organização: Reis, 2010. 
O contato com a natureza é destacado em $73 \%$ das entrevistas na Cachoeira da Porteira e $80 \%$ na Cachoeira Santuário (Fig. 3.). O componente "beleza cênica do local" somente é citado na Cachoeira da Porteira, por $13 \%$ dos entrevistados. No entanto, o componente "contemplação da paisagem" é citado por $20 \%$ dos visitantes entrevistados na Cachoeira da Porteira e 33\% deles na Cachoeira Santuário. O componente "lazer" é destacado com 13\% na Cachoeira Santuário e 7\% na Cachoeira da Porteira. Um dos fatores para que esse último componente seja mais evidente na Cachoeira Santuário, seja o fato de possuírem uma estrutura mínima para dar suporte as práticas de lazer.

Os elementos biofísicos e naturais da paisagem que dão ao lugar seu valor cênico e possibilidade de desenvolvimento de atividades de lazer e recreação possibilitam a conformação de novos produtos turísticos ou mesmo adicionam melhorias à oferta. Dessa forma, quando indagados sobre quais seriam os atrativos das áreas naturais (Fig. 3.) pesquisadas, cerca de $53 \%$ dos entrevistados em ambos os atrativos citaram a "cachoeira" como principal componente da paisagem, seguida das belezas naturais com $40 \%$ de citações nas duas áreas, respectivamente (Fig. 4.). Os outros componentes citados foram particulares aos atrativos, como na Cachoeira da Porteira para qual foram expostos como atrativos as "Rochas Expostas" (13\%), a "Pouca Visitação" da área (7\%) e a "Tranqüilidade" do local (7\%). Para a Cachoeira Santuário foram expostos a "Historia Geológica" do local (7\%) e as "Trilhas" (7\%) existentes no entorno do atrativo principal.

Cachoeira da Porteira

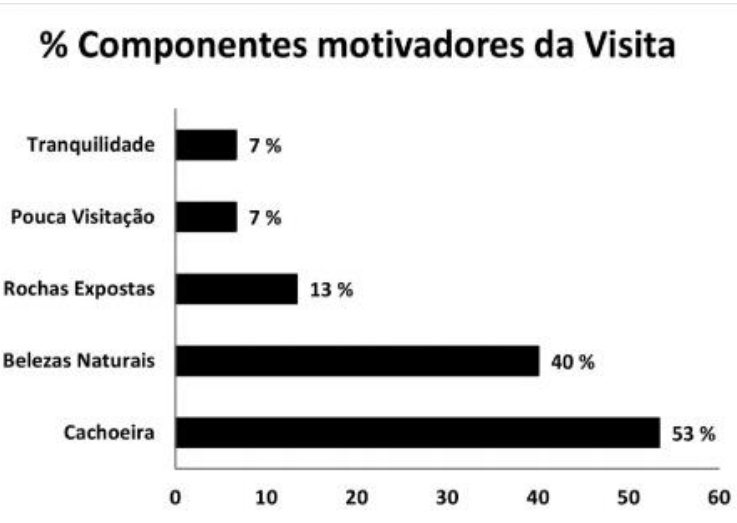

a
Cachoeira Santuário

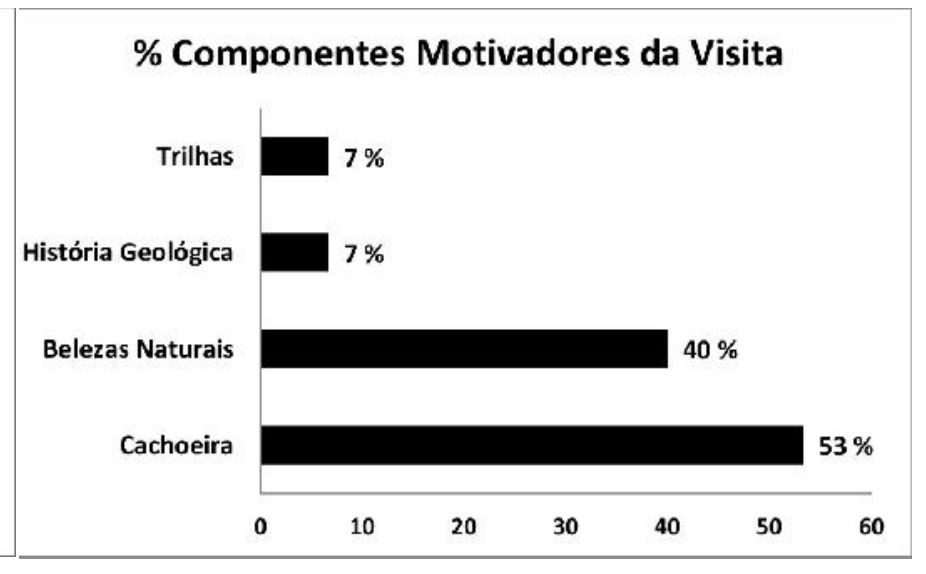

b

Fig. 3. - Atrativos das áreas naturais pesquisadas: a) Entrevistados da Cachoeira da Porteira; e b) Entrevistados da Cachoeira do Santuário. Organização: Reis, 2010. 


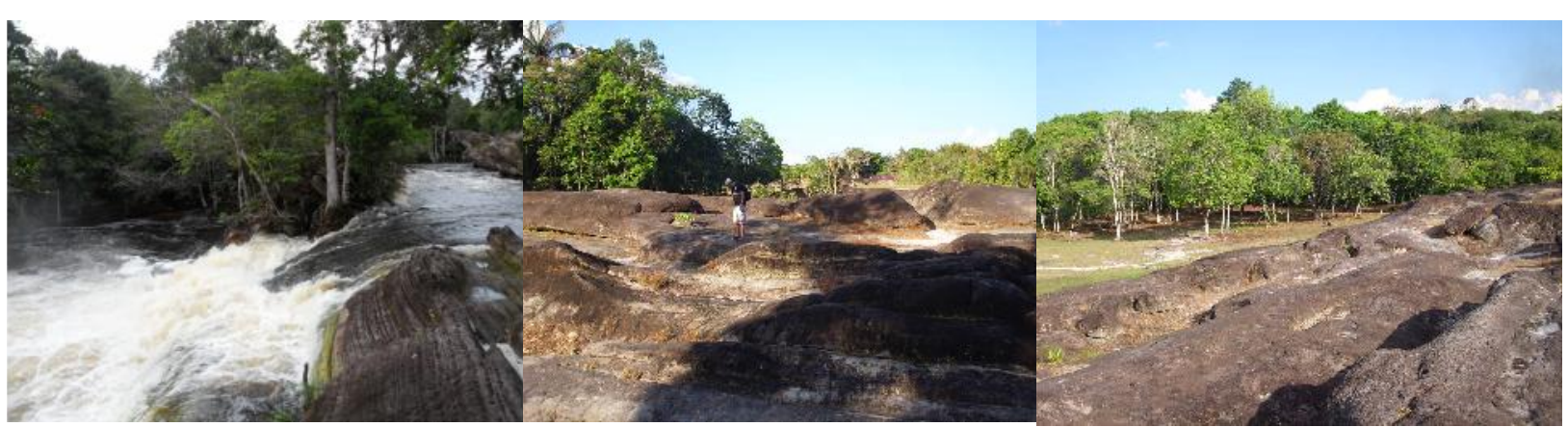

$\mathrm{a}$

b

C

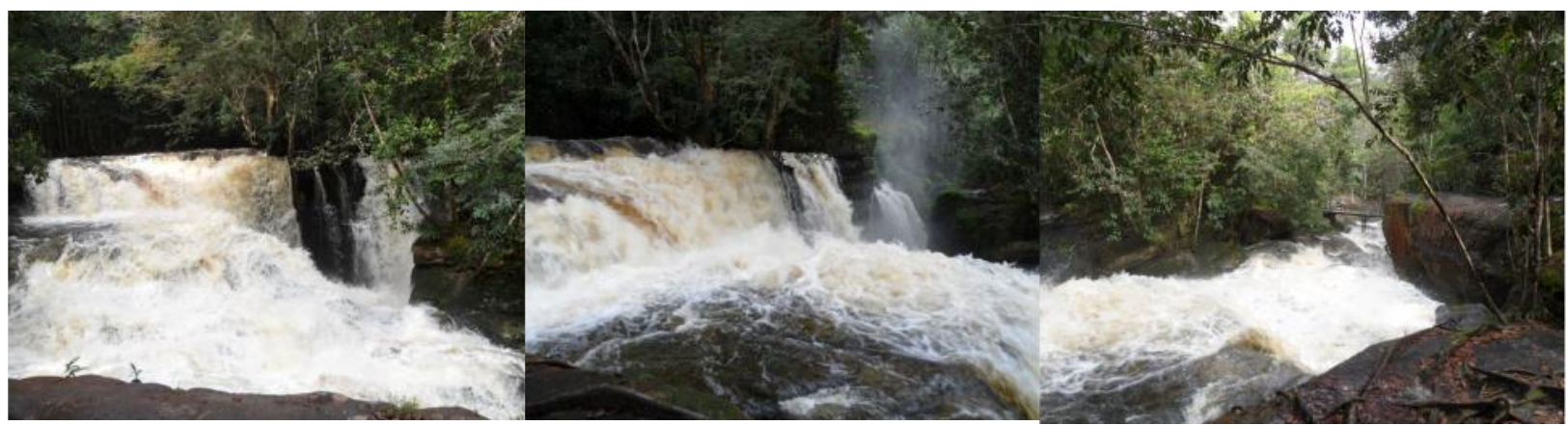

d

e

f

Fig. 4. - Atrativos das áreas naturais pesquisadas: a, b, c) Complexo Cachoeira da Porteira; d,e,f) Cachoeira do Santuário. Fonte: Reis, J.R.L, 2010.

Quanto à percepção sobre a infraestrutura das áreas (Fig. 5.), em ambos os atrativos os visitantes citaram com maior freqüência a existência de infraestrutura básica sem descaracterizar a área, com 47\% para Cachoeira da Porteira e 67\% para Cachoeira Santuário. Observou-se que cerca de $40 \%$ dos entrevistados na Cachoeira da Porteira destacaram que a área não apresenta infraestrutura adequada para estadia e alimentação dos visitantes e 13\% afirmam que há infraestrutura mínima, porém não supre a demanda de visitação (Fig. 6.). A maior frequência deste item para Cachoeira Santuário deve-se ao fato de haver uma infraestrutura estabelecida fora da área de abrangência do atrativo (Fotos de 7 a 10). 
Cachoeira da Porteira

\% Situação da Infraestrutura do Local

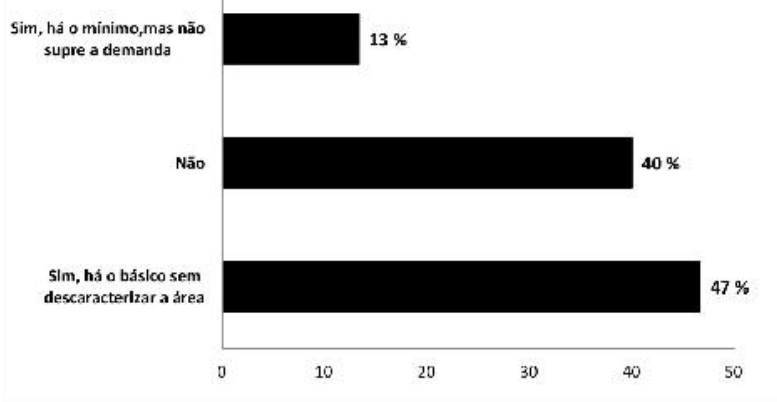

a

\section{Cachoeira Santuário}

\% Situação da Infraestrutura do Local

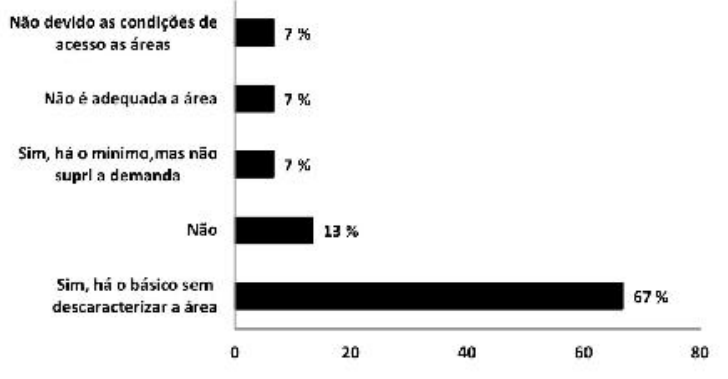

b

Fig. 5. - Infraestrutura das áreas naturais: a) Entrevistados da Cachoeira da Porteira; e b) Entrevistados da Cachoeira do Santuário. Organização: Reis, 2010.

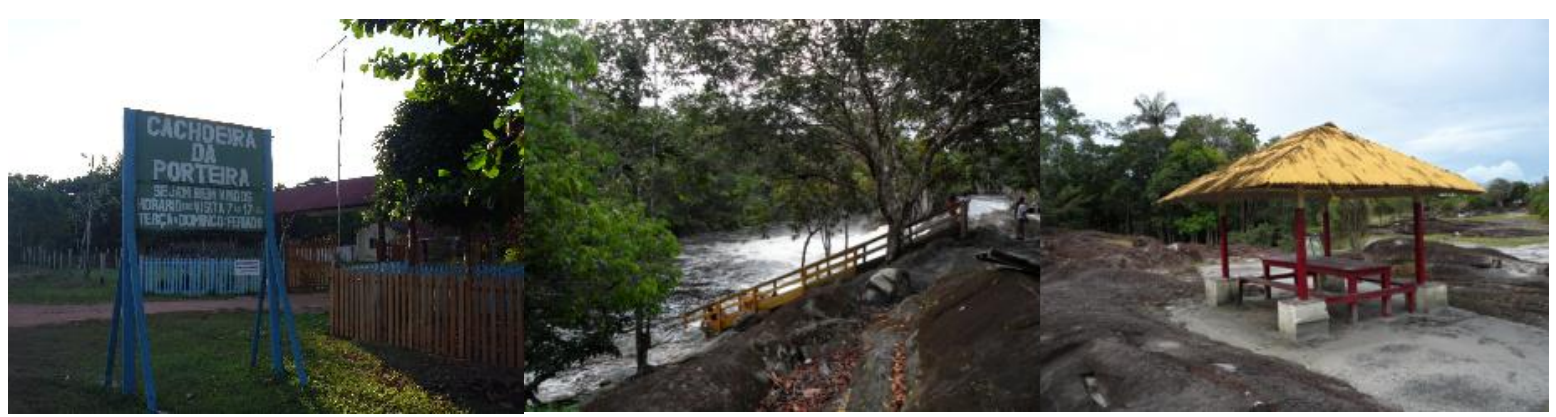

a

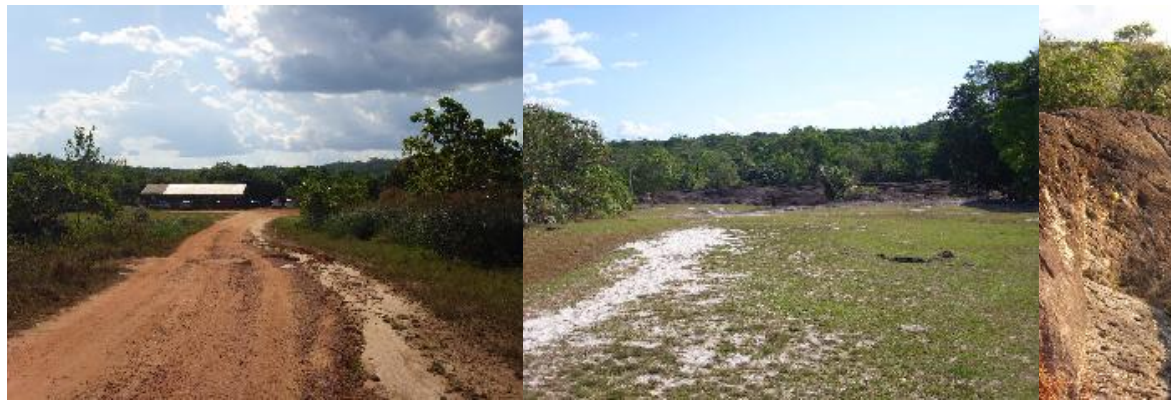

d b

c

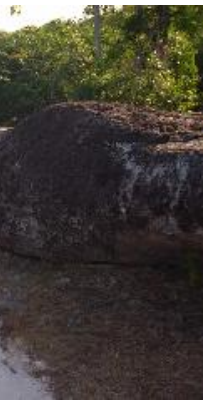

f 


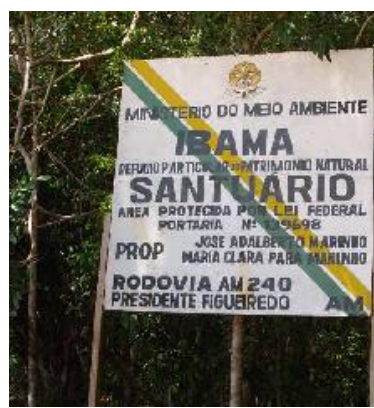

$\mathrm{g}$

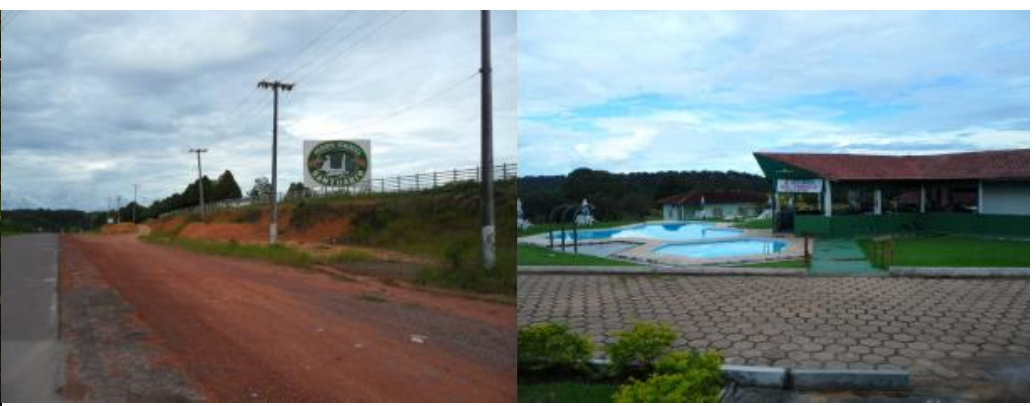

$\mathrm{h}$

i

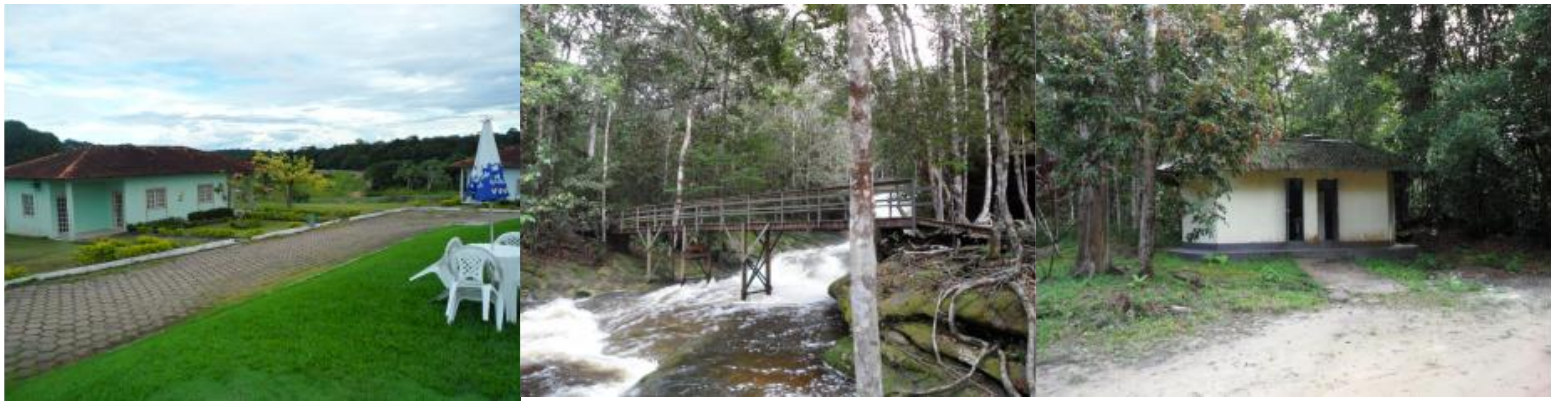

$\mathrm{j}$

1

$\mathrm{m}$

Fig. 06 - Infraestrutura dos locais: Cachoeira da Porteira - a) Placa de Localização, b) Ponte de Acesso, c) Mesa com Cobertura, d) Ramal de Acesso e estacionamento, e) Área para camping, f) Trilhas entre os Arenitos; Cachoeira Santuário - g) Placa - RPPN Santuário; h) Placa de Localização do Empreendimento Hoteleiro Cachoeira Santuário, i)

Restaurante, j) Pousadas e acessos, 1) Ponte de acesso; m) Banheiro na Entrada do Atrativo. Fonte: Reis, J.R.L, 2010.

Sobre as condições de conservação ambiental das áreas (Fig. 7.), cerca de $13 \%$ dos entrevistados apontaram que a Cachoeira da Porteira não está em bom estado de conservação. Na cachoeira Santuário 27\% dos entrevistados destacaram o mesmo item, apesar da área estar em uma reserva privada. Uma das explicações para esse resultado está no entendimento pelo visitante da abrangência geográfica onde está localizado o atrativo e o grau de instrução dos mesmos, o que lhe garante uma amplitude da escala de análise sobre os possíveis impactos ambientais existentes na área. Em campo, pode-se perceber que a Cachoeira da Porteira é a que apresenta maior evidencias de impactos ambientais, em relação a Cachoeira Santuário (Fig. 08.). 
Cachoeira da Porteira

\section{Área em Bom Estado de Conservação?}

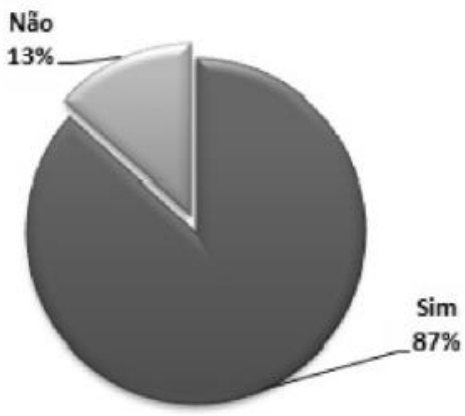

a

\section{Cachoeira Santuário}

Área em Bom Estado de Conservação?

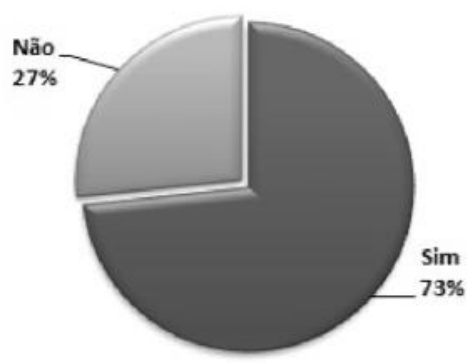

B

Fig. 7. - Estado de conservação das áreas naturais: a) Entrevistados da Cachoeira da Porteira; e b) Entrevistados da Cachoeira do Santuário. Organização: Reis, 2010.

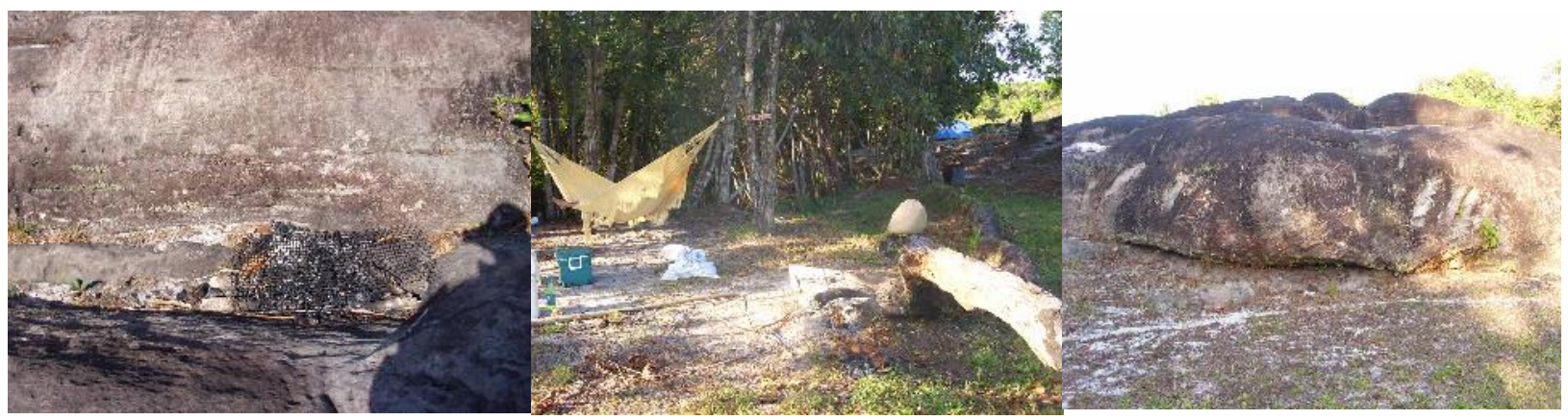

a

b $\mathrm{c}$

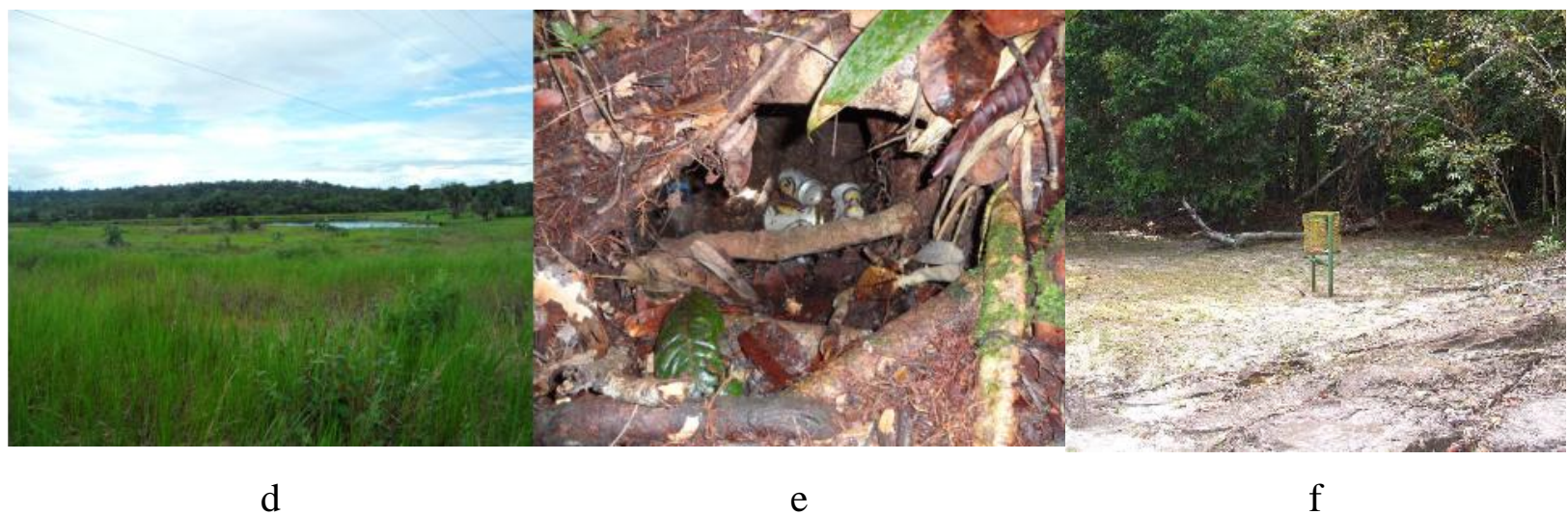

Fig. 08. - Impactos ocasionados nos locais: Cachoeira da Porteira - a) Resíduos de Fogueira entre os arenitos, b) Restos de Fogueira, c) Pichações nos arenitos; Cahcoeira Santuário - d) Área em regeneração, e) Resíduos Sólidos inseridos pelos visitantes nas raizes das árvores, f) Lixeiras. Fonte: Reis, J.R.L, 2011. 
Quando indagados sobre se há segurança e orientação durante a permanência nas áreas (Fig. 9.), 53\% dos visitantes da Cachoeira da Porteira destacaram que não há esses serviços, enquanto que $47 \%$ evidenciaram o mesmo item na Cachoeira Santuário. Um dos pontos de maior destaque é a ausência de vigilância e dos procedimentos de administração de visitantes, o que inviabiliza que o mesmo tenha maior comodidade e tranqüilidade durante a permanência na área.

Cachoeira da Porteira

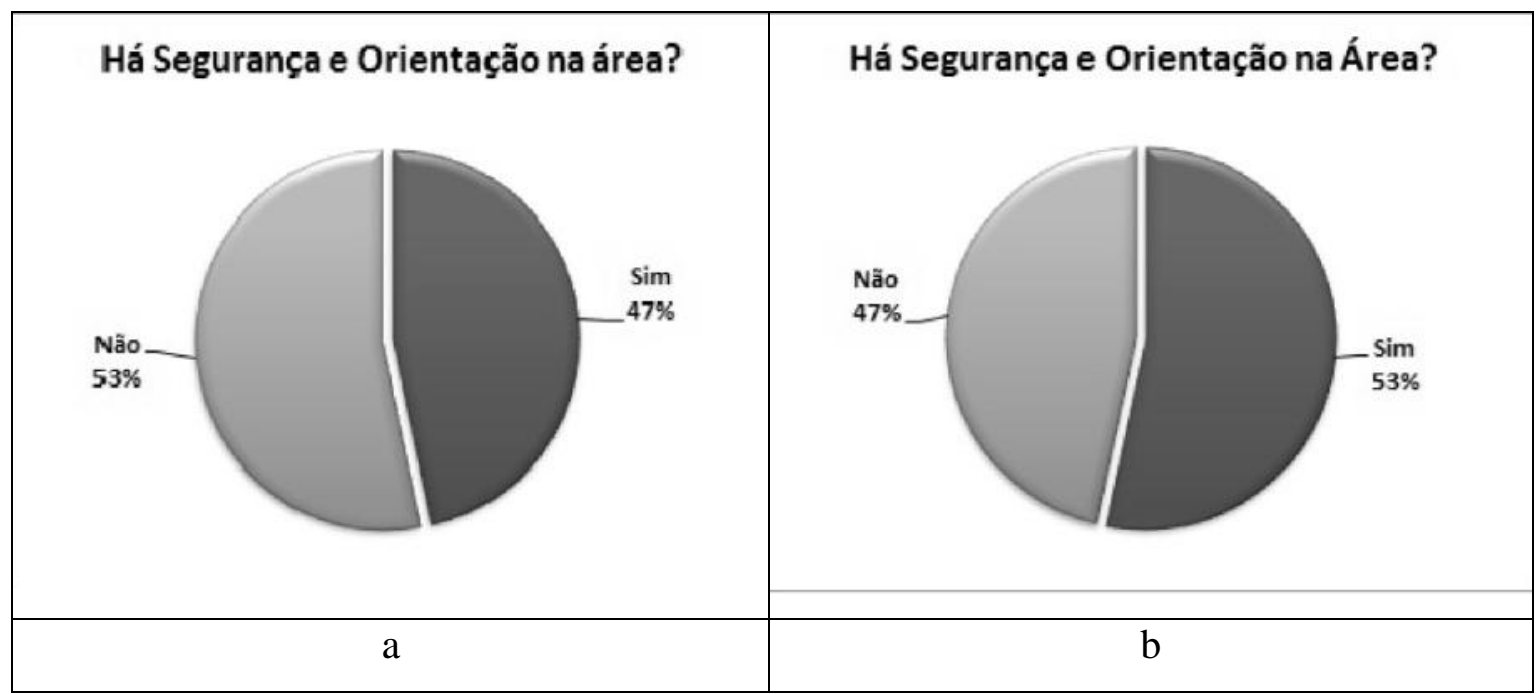

Fig. 9. - Segurança e Orientação durante a permanência nas áreas naturais: a)

Organização: Reis, 2010.

Nos registros de segurança (Fig. 10.), cerca de 60\% dos entrevistados destacaram a necessidade de se estabelecer rotina de salva-vidas e guias/condutor-instrutor para acompanhamento e monitoramento dos visitantes e também a implantação de sinalização interna no local. Além disso, a realização de vigilância nos locais de camping (com 47\% de frequiência), a fim de evitar roubos, e a roteirização dos atrativos (que facilitaria a visitação aos demais atrativos da área). Outro aspecto, bastante evidenciado por $40 \%$ dos entrevistados é a necessidade de construção de infraestrutura mínima, como banheiros biológicos (citado por $20 \%$ dos entrevistados), acampamento e restaurante que são inexistentes na área. 


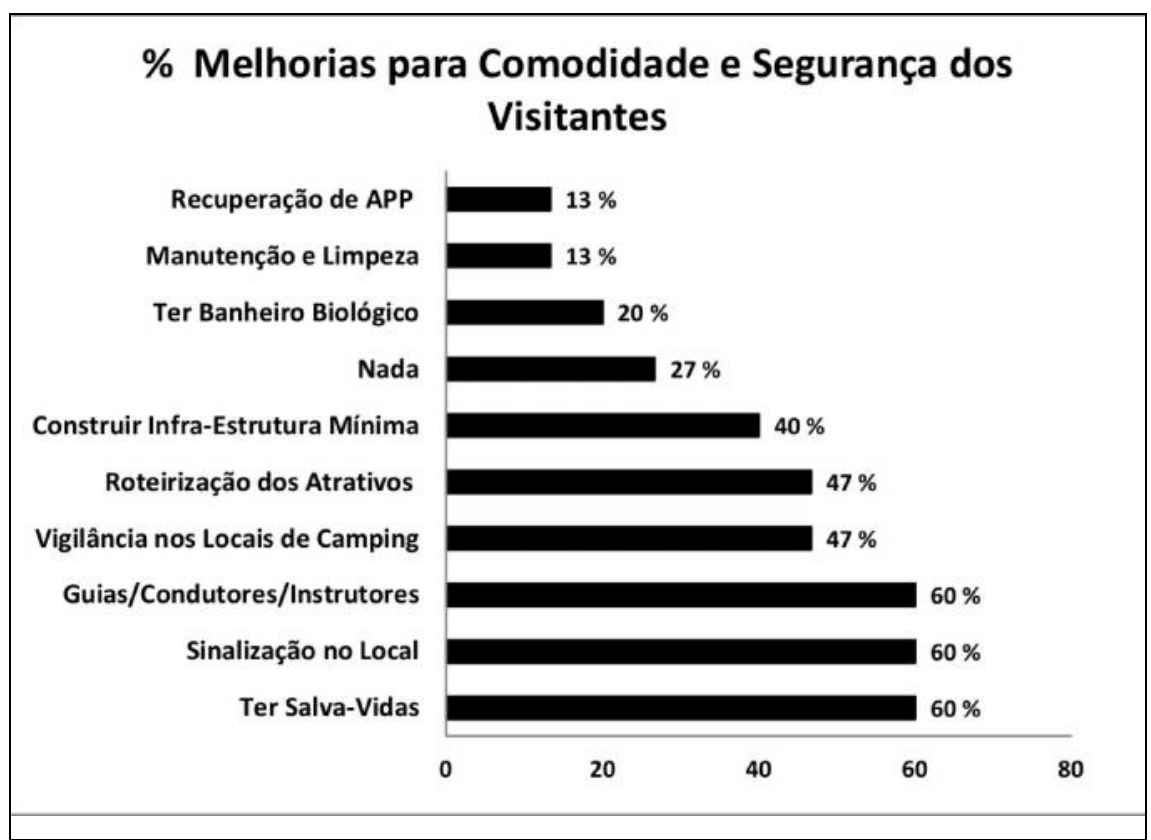

Fig. 10. - Melhorias para maior comodidade dos visitantes na Cachoeira da Porteira. Organização: Reis, 2010.

A manutenção e limpeza é um dos principais problemas vinculados a conservação da Cachoeira da Porteira, citado por $13 \%$ dos visitantes, assim como, providências para recuperação da vegetação ciliar do curso d'água que origina a cachoeira, que atualmente encontra-se pisoteado e desflorestado, sendo uma ameaça para integridade ambiental da área, e é uma área de preservação permanente (APP), porém como a atividade desenvolvida na área até o momento não está licenciada pelo órgão ambiental, então as APP não foram delimitadas e nem conservadas.

Para Gadelha e Alecrim (2006), na cachoeira da Porteira, os impactos que mais chamam a atenção são: as inscrições nas rochas areníticas, assoreamento causado pela retirada da mata ciliar e destinação inadequada dos resíduos sólidos. Salientam que por ser um atrativo voltado à prática de camping, no qual os visitantes levam seus alimentos e bebidas, verificou-se o abandono de restos de alimentos ao ar livre, atraindo insetos, bactérias e provocando mau cheiro. Assim, diante dos impactos ambientais constatados, esses autores sugerem ainda algumas medidas para mitigá-los e preveni-los: 1) implantar infraestrutura adequada, como, por exemplo, sanitários e lixeiras; 2) realizar estudo da demanda e, conseqüentemente, efetuar o registro de visitantes e calcular a capacidade de carga; 3) analisar o solo para verificar compactação e estabelecer as medidas mitigadoras para preservar o solo frágil do entorno da 
cachoeira; 4) analisar os recursos hídricos para verificar a qualidade da água; e 5) adicionar sinalização nas laterais da trilha de acesso, indicando o caminho e as distâncias, além dos painés interpretativos. Cabe destacar que as medidas sugeridas pelos mesmos são primordiais para ordenamento ambiental e turístico do atrativo, constatado junto aos visitantes da Cachoeira da Porteira, que continua em precárias condições de funcionamento.

Na Cachoeira Santuário (Fig. 11.) os itens como "Estabelecimento de rotina de salva-vidas" e "Guias/condutores/instrutores" para monitoramento dos visitantes foram os mais citados por $67 \%$ dos visitantes, assim como a "Implantação de sinalização", seguidos pelo item "Roteirização dos atrativos" com 53\%, inexistente na área. Cabe salientar que os itens construção de infraestrutura mínima, construção de banheiros biológicos, manutenção e limpeza da área e atendimento mais eficaz, tiveram freqüência de $7 \%$, respectivamente. Observou-se que a área da Cachoeira Santuário está em melhores condições de atender ao público que o outro atrativo, o mesmo, ainda não possui, contudo, licenciamento ambiental.

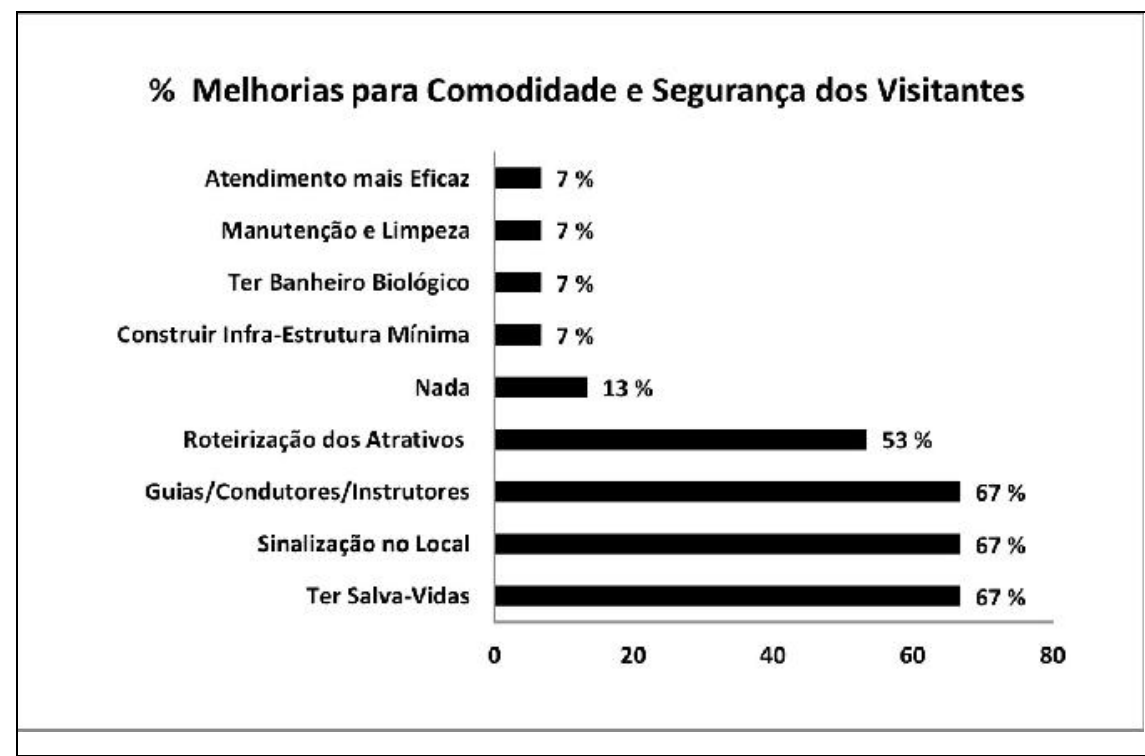

Fig. 11. - Melhorias para maior comodidade dos visitantes na Cachoeira Santuário. Organização: Reis, 2010.

Para a Cachoeira Santuário, Gadelha e Alecrim (2006), destacaram que as alterações ambientais mais significativas foram as oriundas das obras de infraestrutura, principalmente 
no que concerne à estruturação sanitária, onde parte dos efluentes é lançada sem tratamento entre a vegetação, sendo possível a contaminação de corpos d'água. Citam também, a existência de dispersão de resíduos sólidos e destruição da mata ciliar, com ocorrência de assoreamento. Diante dos impactos ambientais constatados, os autores sugeriram algumas medidas para mitigá-los e preveni-los: a) adequar a estrutura sanitária, objetivando a higiene e conservação dos recursos hídricos e hidrogeológicos; b) realizar estudo da demanda e, conseqüentemente, efetuar o registro de visitantes e calcular a capacidade de carga; c) analisar o solo para verificar compactação e estabelecer as medidas mitigadoras para preservar o solo frágil do entorno da cachoeira; d) analisar os recursos hídricos para verificar a qualidade da água; e) realizar manutenção da trilha de acesso, renovando as toras de madeira desgastadas, e colocando bancos para descanso; e f) adicionar sinalização nas laterais da trilha, indicando o caminho e as distâncias, além de painéis interpretativos.

Evidenciou-se que a RPPN Santuário ainda não possui plano de manejo, apesar de já possuir 11 anos de instituição. Grande parte dos empreendedores transforma parte de suas propriedades em RPPN não somente devido à decisão voluntária de querer proteger a biodiversidade, mas principalmente devido ao marketing ambiental que esse procedimento promove na ocasião da divulgação do empreendimento. Fora disso, observa-se por outro lado a ausência de monitoramento por parte do órgão ambiental que credenciou a RPPN, no caso o Instituto Chico Mendes de Conservação da Biodiversidade (ICMBio), para o qual o proprietário da reserva privada encaminha anualmente relatório de atividades.

Com relação à preferência de áreas naturais para interesse de visitação turística, os visitantes da Cachoeira da Porteira (Fig. 12.) destacaram mais interesse por atrativos como Cachoeira (100\%); grutas e corredeiras (53\%); floresta densa, sítio arqueológico e áreas para pesca (47\%); e áreas com rios, lagos e floresta de campinarana (40\%) (Fig. 13.).

Como atrativos secundários ficaram áreas como as de reprodução de fauna, cavernas e rochas expostas $(33 \%)$ e sítio histórico (27\%). As áreas destacadas com menor interesse foram aquelas com evidente processo de fragmentação e de pastagem (7\%). Observa-se que o público entrevistado tem mais interesse nas atividades de lazer e recreação nessas áreas, por isso observam-se freqüências de citações continuas em três atrativos distintos. 


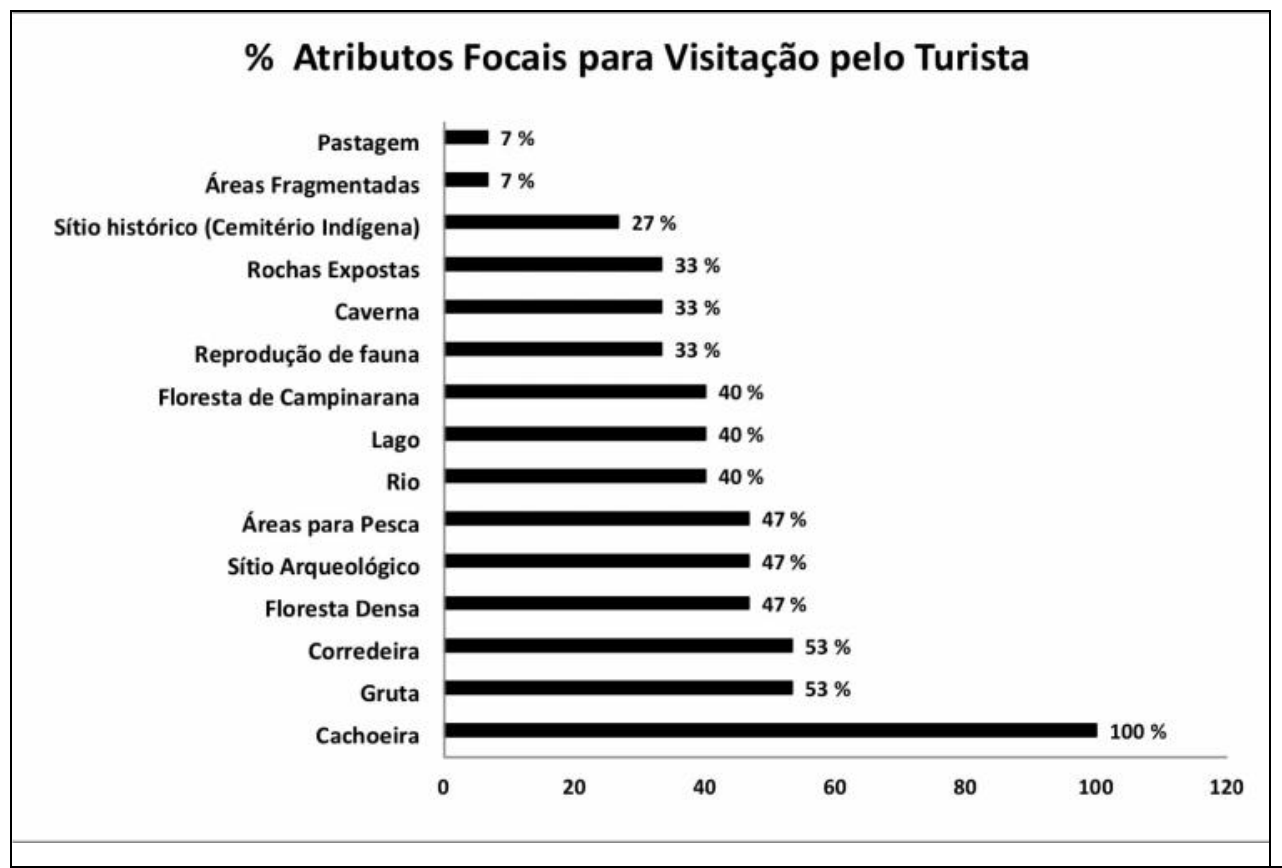

Fig. 12. - Preferências de atrativos naturais para visitação pelos entrevistados da Cachoeira da Porteira. Organização: Reis, 2010.

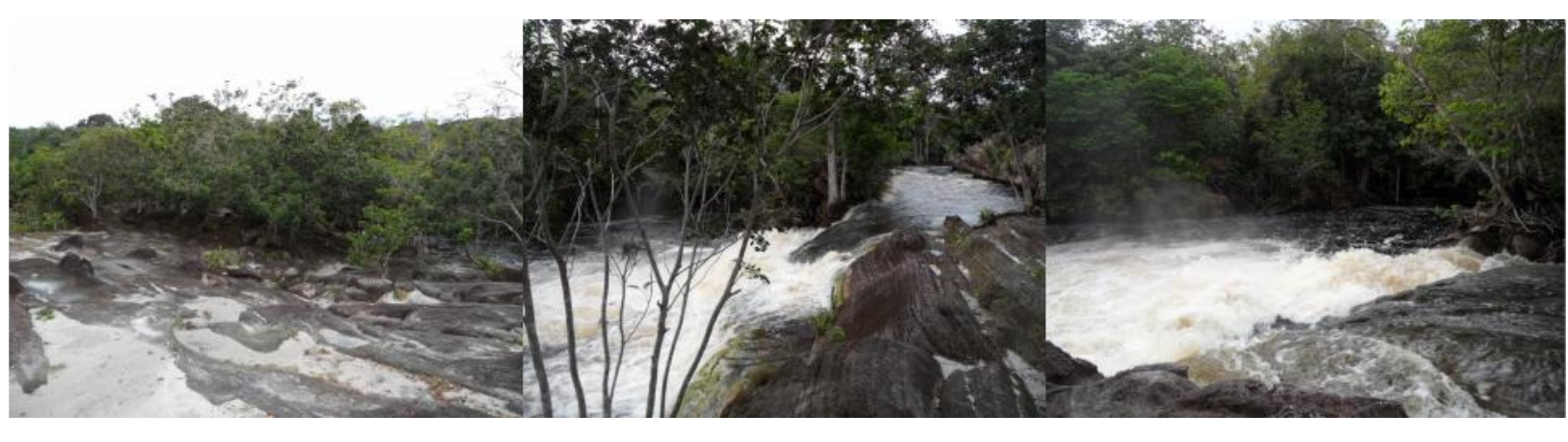

a

b

$\mathrm{c}$

Fig. 13 - Cachoeira da Porteira: a) Arenitos, b) Queda-D'água, c) Panorâmica Queda-D'água. Fonte: REIS, J.R.L, 2010.

Os visitantes da Cachoeira Santuário (Fig. 14.) optaram por atrativos de maior interesse como as cachoeiras (93\%); cavernas (67\%); grutas (53\%); e corredeiras (47\%). Demonstrando-se com isso que esses visitantes atendem um perfil segmentado de turismo e seus interesses estão mais voltados às formações espeleológicas (Fig. 15). 


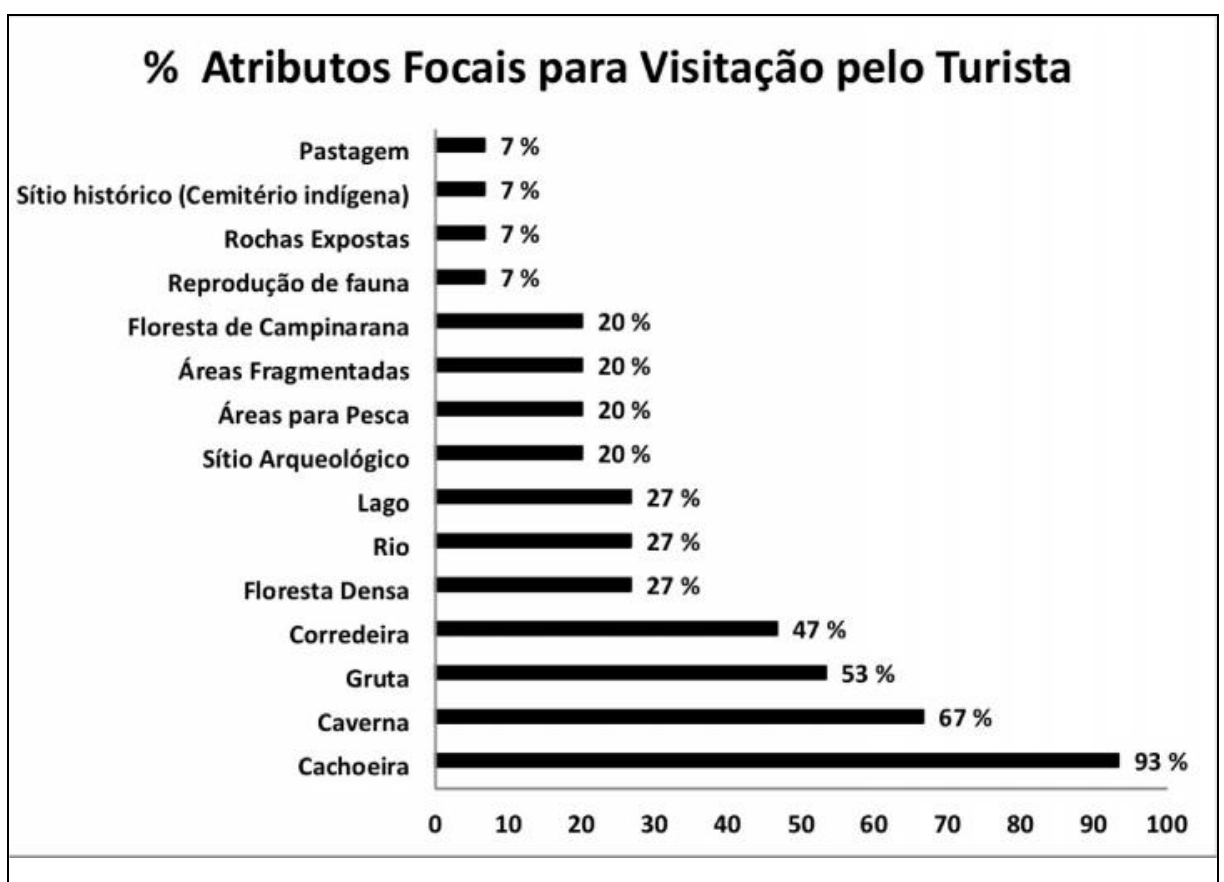

Fig. 14. - Preferências de atrativos naturais para visitação pelos entrevistados da Cachoeira Santuário. Organização: Reis, 2010.

Como atrativos secundários citaram a floresta densa, rios e lago (27\%); sítios arqueológicos, áreas para pesca, áreas com fragmentação florestal e floresta de campinarana (20\%); e áreas para reprodução de fauna, com rochas expostas, sítio histórico e pastagem (7\%).

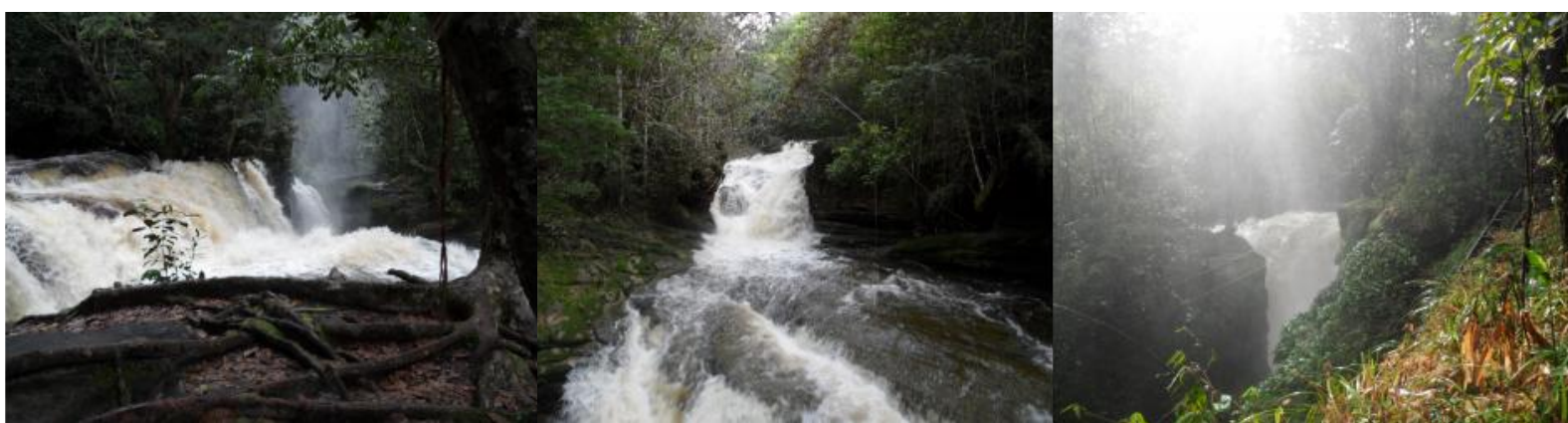

a

$\mathrm{b}$

C

Fig. 15 - Cachoeira Santuário: a) Quedas Centrais desaguando para os demais patamares de arenito, b) Queda-D’água Secundária - Lado Esquedo, c) Panorâmica Queda-D’água - lado direito do Bloco Arenítico. Fonte: REIS, J.R.L, 2010. 
De acordo com os dados do Programa de Cálculo do Desflorestamento da Amazônia (PRODES), no ano de 2008, as áreas de abrangência dos atrativos, Cachoeira da Porteira e Cachoeira Santuário, já estavam bastante impactadas pelo desmatamento principalmente ao longo da margem do Curso (Igarapé) Mutum que é o principal curso d'água que dá origem aos atrativos. Dessa forma, há necessidade emergencial de apoio à recuperação das áreas degradadas ao longo desse curso e também análise de sua balneabilidade.

Quanto à situação fundiária os dois atrativos encontram-se inseridos em um assentamento rural (Projeto de Assentamento Rural Uatumã), merecendo ações de controle e monitoramento ambiental, a fim de inibir a degradação das áreas e favorecer a manutenção ou reestruturação administrativa dos mesmos.

$\mathrm{Na}$ pesquisa verificou-se que as considerações apontadas pelos visitantes deixam claro que as diferenças entre os dois atrativos pesquisados são praticamente mínimas. No entanto, cabe salientar que a Cachoeira Santuário é o atrativo mais estruturado, pois possui infraestrutura física anexa e ainda executa regras mínimas mais consistentes quanto à permanência dos visitantes no atrativo, principalmente, quanto a não permissão de camping e o uso de alimentos e bebidas. Já a Cachoeira da Porteira, como salientam os visitantes, precisa de maior investimento para melhorias em infraestrutura e no gerenciamento da área.

Neste aspecto, cabe citar a ausência de zoneamento das áreas de uso e a implantação de placas de aviso sobre áreas com risco de acidentes, bem como, a inexistência de atendimento de primeiros-socorros e salva-vidas. Esses aspectos são relevantes a partir do momento em que se pretende divulgar essas áreas como um produto turístico, porém devem-se solucionar os entraves que impedem a existência de serviços básicos de apoio e informação pontual aos visitantes durante o processo de visitação. Apesar do Decreto Estadual nº 30.873 , de 28/12/2010, determinar em seu art. $18^{\circ}$. que os visitantes das unidade de conservação estaduais deverão assumir os riscos provenientes de sua conduta, inerentes a prática de atividades em ambientes naturais, mediante a assinatura de termos de específicos quando couber, ressalta-se a importância de que as áreas com atrativos naturais possuam condições as mínimas de segurança aos seus visitantes. 
Outro aspecto notório é que os entrevistados, apesar de grande parte possuir a percepção do avanço da degradação ambiental dos atrativos, não se referiram em nenhum momento ao fato da Cachoeira Santuário estar em uma reserva privada, apesar de existir placa do IBAMA que em 1998 a credenciou como RPPN. Esse aspecto evidencia que melhorias devem ser realizadas na gestão da reserva, que não possui controle e monitoramento sobre a visitação, plano de manejo, plano de uso público, roteirização dos atrativos e sinalização interna. Sendo este quadro observado em maior grau na Cachoeira da Porteira.

Destacou-se nesse cenário, as seguintes perguntas: qual o real interesse de se querer transformar parte da propriedade em RPPN? E quais vantagens em apoio técnico e financeiro esse procedimento trará aos proprietários dessas áreas?. A resposta a essas perguntas talvez traga bons motivos para a melhoria do gerenciamento ambiental e aporte de infraestrutura de apoio à Cachoeira da Porteira, que atualmente está sob uma condição de perigo quanto principalmente aos impactos ocasionados em suas formações rochosas e no entorno de seu curso d'água. Tal fato é prejudicial para a Cachoeira Santuário, já que a Cachoeira da Porteira fica a montante do Igarapé do Mutum, também seu principal curso d'água. Por outro lado, os próprios visitantes não sabem se comportar nessas áreas e não adquiriram a cultura de “interação com o natural”, sem deixar rastros de sua passagem pela área. Apesar das campanhas efetuadas pelo Ministério do Meio Ambiente, como a "Conduta Consciente em Ambientes Naturais" com oito princípios de mínimo impacto. No entanto, não foi observada a eficácia dessa campanha entre os visitantes dos atrativos pesquisados. Nota-se que no que tange a importância da ação de órgãos ambientais no licenciamento e monitoramento ambiental dos atrativos não foi citada por nenhum dos entrevistados, o que sugere que estes possuem pouco poder de atuação na região.

\section{Conclusões}

O trabalho realizado auxiliará na formulação e seleção de melhores critérios para aprimoramento da gestão das áreas, bem como, na identificação de quais ações prioritárias são essenciais para gestão ambiental das mesmas.

Os atrativos pesquisados estão em uma condição de uso intensivo, o que propicia o surgimento de problemas ambientais graves, principalmente, quanto ao fluxo sem controle de 
visitantes e ausência de monitoramento das atividades praticadas por estes durante a permanência nas áreas. Esse fato sugere a inexistência de ações de gestão ambiental e também a precariedade dos serviços a serem oferecidos para maior comodidade e segurança dos usuários.

As demandas identificadas nos dois atrativos ilustram a situação dos demais atributos da APA, assim como em outros atrativos naturais dispersos pela Amazônia, quanto sua operação turística.

De forma geral, cabe salientar a ausência de:

a) Ações de gestão ambiental e de medidas de controle e monitoramento da visitação turística pelos proprietários dos atrativos;

b) Licenciamento ambiental da atividade turística com a expedição de Licença de Operação (LO) para o funcionamento do "empreendimento turístico", mesmo que não possua infraestrutura edificada;

c) Ausência fiscalização e monitoramento ambiental pelo órgão oficial de meio ambiente, assim como, a assinatura e execução pelo proprietário do Termo de Ajustamento de Conduta Ambiental (TACA), quando couber;

d) Elaboração e implementação das ações previstas no Plano de Controle Ambiental (PCA) e no Plano de Recuperação de Áreas Degradadas (PRAD);

e) Credenciamento do proprietário pelo órgão oficial de turismo local e estadual e autorização para funcionamento do local para visitação turística, assim como, para operacionalização de alimentação e bebidas, pois o que há é apenas a anotação da localização (endereçamento) do local já em operação turística;

Além disso, observa-se que não há por parte do Poder Público, ações permanentes de capacitação e financiamento aos proprietários para a gestão ambientalmente adequada do turismo em atrativos naturais, assim como, para a execução da própria atividade turística. Como propostas de ações, sugere-se:

- Desenvolvimento de um Programa de Geração de Renda do Turismo para proprietários com atrativos naturais de grande relevância/representatividade (principalmente os que dependem 
do uso turístico do atrativo diretamente para renda familiar) dando suporte para Infraestrutura adequada com as condições biofísicas dos locais, elaboração dos Planos (instrumentos de gestão) e de divulgação;

- Apoio ao desenvolvimento dos estudos necessários para o planejamento e/ou adequação/ordenamento do turismo (Capacidade de Carga, Capacidade Paisagística, Diretrizes para conduta da visitação - normas e orientações, recursos humanos - quantidade suficiente e capacitação, etc), visando consolidar o Processo de Monitoramento da Visitação;

- Recuperação de áreas degradadas/danificadas pela visitação com o apoio ao desenvolvimento de PRAD's e medidas de mitigação;

- Zoneamento da visitação delineado a partir do Estudo de Capacidade Paisagística;

Salienta-se que a solução a essas demandas está focalizada na execução do Programa de Uso Público do Plano de Gestão da APA Caverna do Maroaga, o qual deverá propiciar a regulamentação e ordenamento do uso público dos atrativos e a definição de como e qual será o tratamento adequado, recomendações e as obrigações a serem atendidas pelos visitantes e proprietários para uso turístico desses locais; além do atendimento ao disposto no Decreto Estadual no ${ }^{\circ}$ 30.873, de 28/12/2010.

\section{Referências}

AMAZONAS. Decreto Estadual $n^{o}$. 30.873, de 28 de Dezembro de 2010. Estabelece as diretrizes de uso público para as Unidades de Conservação Estaduais do Amazonas. Manaus: Imprensa Oficial do Estado. 2010.

CORIOLANO, L. N. M. T. Bases conceituais do desenvolvimento e do ecoturismo. In: MACHADO, O. T. M. Turismo e ambiente: temas emergentes. Cap. 1. Campinas-SP: Editora Alínea, 2006.

GADELHA, E. M. \& ALECRIM, J. D. Turismo: impactos nos aspectos geomorfológicos da Área de Proteção Ambiental Presidente Figueiredo Caverna do Maroagal AM. Caderno de Turismo Virtual. ISSN: 1677-6976. Vol. 6, $\mathrm{N}^{\circ}$ 2, $2006 \quad$ b. In:. subterraneo.com.br/index.php?option=com_docman\&task=doc_download\&gid=268>. Acesso em: 09/01/2009.

GRAHN, A. Administração de visitantes em unidades de conservação. In: NELSON, S. P. \& PEDREIRA, E. M. (Org.). Ecoturismo: Práticas para turismo sustentável. Manaus: Editora Vale/UniNorte, 2004.

KINKER, S. Ecoturismo e conservação da natureza em parques nacionais. Papirus Editora: Campinas/SP, 2002. 
MAGRO, T. C. Atuação profissional em uso público: ensino superior e capacitação no Brasil. Anais do VI Congresso Brasileiro de Unidades de Conservação. Curitiba-PR: Fundação O Boticário de Proteção da Natureza, 2009.

MAGRO, T. C. Impactos do uso público em uma trilha no planalto do Parque Nacional do Itatiaia. Tese (Doutorado). Escola de Engenharia de São Carlos - Universidade de São Paulo, 1999. 135 pag. In: 〈http://www.ipef.br/servicos/teses/arquivos/magro,tc.pdf〉.

MARANGONI, A. M. M. C. Questionários e entrevistas: algumas considerações. In: Venturi, Luis Antonio Bittar. Praticando a geografia: técnicas de campo e laboratório. São Paulo: Oficina de Texto, 2005.

MARCONI, M. A. Técnica de pesquisa: planejamento execução de pesquisas, amostragens e técnicas de pesquisas, elaboração, análise e interpretação de dados. 5. ed. São Paulo: Altas, 2002.

MMA. Ministério do Meio Ambiente. Diretrizes para visitação em Unidades de Conservação. Secretaria de Biodiversidade e Florestas. Diretoria de Áreas Protegidas. Brasília: Ministério do Meio Ambiente, 2006 b.

MMA. Ministério do Meio Ambiente. Portaria $n^{\circ} .120$, de 12 de abril de 2006 - aprova o documento "Diretrizes para visitação em Unidades de Conservação". Brasília: Ministério do Meio Ambiente, 2006 a.

PÁDUA, M. T. J. Área de Proteção Ambiental. In: Direito Ambiental das Áreas Protegidas: O Regime Jurídico das Unidades de Conservação. Antônio Herman Benjamin (org.). Rio de Janeiro: Forense Universitária, 2001.

QUEIROZ, O. T. M. M. Atividades turísticas e recursos naturais. In: MACHADO, O. T. M. Turismo e ambiente: temas emergentes. Cap. 1. Campinas-SP: Editora Alínea, 2006.

REIS, J. R. L. \& FREITAS, M. S. Territorialidades e uso público dos recursos turísticos naturais na Amazônia Central. In: $1^{o}$ Congresso de Ecoturismo da Amazônia, 2008, Manaus/AM. Anais do $1^{o}$ Congresso de Ecoturismo da Amazônia. Manaus/AM: Departamento de Geografia - Universidade Federal do Amazonas, 2008.

REIS, J. R. L.; PINHEIRO, E. S.; MACEDO, M. A. Evolução do desflorestamento (1990-2006) em Áreas Protegidas da Amazônia Central. In.: Anais do VIII Seminário de Atualização em Sensoriamento Remoto e Sistemas de Informações Geográficas aplicados a Engenharia Florestal, Curitiba, 07 a 09 de outubro de 2008; Organizadores: Attilio Antonio Disparati, João Roberto dos Santos. Curitiba: FUPEF, 2008.

RIBEIRO, J. D. Ecoturismo: Sustentabilidade na Amazônia. In: RIVAS, A. \& FREITAS, C. E. de C. (Orgs.). Amazônia: uma perspectiva interdisciplinar. Manaus/AM: Editora da Universidade do Amazonas, 2002.

RONCERO-SILES, M. F. Modelagem espacial para atividades de visitação pública em áreas naturais. Dissertação (Mestrado) - Instituto de Biociências da Universidade de São Paulo. São Paulo: Departamento de Ecologia/Universidade de São Paulo, 2003. In: <http://www.teses.usp.br/teses/disponiveis/41/41134/tde-23092004-160650/>. Acesso em: 20/02/2008.

SESSEGOLO, G. C.; PRIES, D. C.; ROCHA, L. F. S.; ROCHA, Ricardo Pinto da; e ZAKRZEWSKI, D. P. Manejo da Caverna do Maroaga, Presidente Figueiredo/AM. IV Congresso Brasileiro de Unidades de Conservação (1.:2004:Curitiba). Anais. V 1. Curitiba: Fundação O Boticário de Proteção à Natureza: Rede Nacional Pró Unidades de Conservação, 2004. 
TAKAHASHI, L. Y. \& MILANO, M. S. Preferências e percepção dos visitantes em relação aos impactos de uso público no Parque Estadual Pico do Morumbi e na Reserva Natural Salto Morato. Turismo Visão e Ação. V. 11. Balneário Camboriú, 2002. In: <http://siaiweb06.univali.br/seer/index.php/rtva/article/view/1239>. Acesso em: 01/12/2009.

TAKAHASHI, L. Y. Caracterização dos visitantes, suas preferências e percepções e avaliação dos impactos da visitação pública em duas unidades de conservação do Estado do Paraná. 1998. 129f. Tese (Doutorado) - Universidade Federal do Paraná, Curitiba, 1998.

TAKAHASHI, L. Y.; MAGRO, T. C. ; BRAMBILLA, M. Seminário: Uso público em unidades de conservação. In: Anais do II Congresso Brasileiro de Unidades de Conservação. Campo Grande: Rede Nacional Pró-Unidades de Conservação: Fundação O Boticário de Proteção da Natureza, 2002.

TAKAHASHI, L. Y. Uso público em unidades de conservação. Cadernos de Conservação: ano 2. n. 2. Curitiba-PR: Fundação O Boticário de Proteção da Natureza, 2004.

WEARING, S. \& NEIL, J. Ecoturismo: impactos, potencialidades e possibilidades. 1. ed. Brasileira (Tradução - Carlos David Szlak). Barueri-SP, 2001.

YIN, R.K. Estudo de Caso: Planejamento e métodos. $2^{\mathrm{a}}$ ed. Porto Alegre: Bookeman, 2001.

Recebido em: 20/12/2011 (1a versão) 17/05/12 (2a versão)

Aprovado em: 29/09/2012 